\title{
Anchorage Zone Stresses Model of Interior Diaphragm for Segmental Box Girder Bridge
}

\author{
Ghassan M. Werdina1', Omar Q. Aziz² \\ ${ }^{1}$ Department of Dams and Water Resources, Salahaddin University, Erbil, Kurdistan Region, Iraq, ${ }^{2}$ Department of Civil Engineering, College \\ of Engineering, Salahaddin University, Erbil, Kurdistan Region, Iraq.
}

\section{*Correspondence author: Ghassan M. Werdina, Department of Water Resources Engineering, College of Engineering, Salahaddin University, Erbil, Kurdistan Region, Iraq. E-mail: ghassan.werdina@ su.edu.krd}

Received: 16 May 2019

Accepted: 03 September 2019

Published: 01 December 2019

DOI

10.25156/pti.v9n2y2019.pp171-177

\section{A B S TR A C T}

Post-tensioning tendons in segmental box girder bridges are usually anchored in very massive diaphragms. This paper presents an analytical investigation of the anchorage zone stresses for an interior pier diaphragm and a rectangular block model (model of diaphragm anchorage zone). The failure load and load-displacement relation for the two cases were compared, a typical diaphragm for a segmenta box girder bridge with external prestressing tendons and rectangular block model were analyzed by finite element program (ABAOUS). The anchorage devices were subjected to a prestressing design load which was based on the ultimate strength of the tendons. The magnitude and distribution of stresses were plotted through different paths for both the diaphragm and the block model; also the contours of stress distribution for the diaphragm and block model were compared. The results showed that the stresses and failure load for the diaphragm and rectangular block model were very close.

Keywords: Anchorage zone; Bridge; Diaphragm; Post-tensioning; Segmental box girder

\section{INTRODUCTION}

The use of post-tensioned concrete allows for longer spans and smaller cross-sections in structures, especially bridges. Post-tensioned girders are subjected to a high concentration of compressive stresses at the anchorage zone due to the transfer of prestressing force at the girder end through bearing plates and anchors (Tawfiq and Robinson, 2008). There are three critical regions within the anchorage zone (Breen et al., 1994; Sanders 1990; Burdet, 1990). The first is directly ahead of the concentrated force where the concrete is subjected to high bearing and compressive stresses. The second extends a certain distance ahead of the anchorage device where the concrete is subjected to lateral tensile stresses. These tensile stresses are called "bursting stresses" and are due to the deviation of the compressive stresses parallel to the force. The third is found along the edge of the member that is being loaded where the concrete is subjected to local tensile stresses, and these tensile stresses are known as "spalling stresses."

If the post-tensioned anchorage zone is not properly detailed and designed to withstand the forces and stresses which develop, failure of the anchorage zone can occur, and if there is inadequate confinement reinforcement in the local zone cracking, crushing, and spalling of concrete may occur (Johnson, 2006).
There are three analysis methods for the stresses in the anchorage zone that include Finite Element analysis, Strutand-Tie-Model, and approximate method (AASHTO, 2017).

In the present investigation, a comparison of stresses in anchorage zone of an interior pier diaphragm with a rectangular block model (cut from its anchorage zone) is presented. Before the comparison, a typical segmental bridge and its interior pier diaphragm were designed by Midas software according to American Association of State Highway Transportation Officials (AASHTO, 2017).

\section{PROBLEM STATEMENT}

This paper intends to compare stresses of anchorage zone of an interior pier diaphragm for segmental box girder bridge with a rectangular block model cut from its anchorage zone. The aim of this paper is to simplify the modeling of the anchorage zone and assists in the analysis of the anchorage zone for this type of diaphragms.

\section{RESEARCH METHODOLOGY}

This study analyses the stresses numerically with 3D solid element using ABAQUS software used to compare stresses, strain, and failure load in the anchorage zone of interior 
pier diaphragm and rectangular block models. Non-linear finite element analysis is used to have a comprehensive stress analysis in the anchorage zone of these two models.

\section{DESIGN OF A TYPICAL SEGMENTAL BOX GIRDER BRIDGE AND INTERIOR PIER DIAPHRAGM}

\section{Design of a Typical Segmental Box Girder Bridge}

A typical two-span segmental bridge with a total length of $61 \mathrm{~m}$ was designed using Midas-Civil software. As shown in Figure 1a, four external post tensioning tendons each with 19-12.7 $\mathrm{mm}$ strands were used, and transverse prestressing for the deck slab included tendons with 4-12.7 mm strands every $0.5 \mathrm{~m}$. Standard American Segmental Bridge Institute sections type 2400-1, with $8.4 \mathrm{~m}$ deck width were used for the diaphragms, deviators and other bridge segments, and the cross sections of the bridge are shown in Figure $1 \mathrm{~b}$ and $\mathrm{c}$. The bridge had two lanes and was designed according to AASHTOLRFD (AASHTO, 2017; FDOT, 2017; FDOT, 2018).

\section{Design of Interior Pier Diaphragm}

The interior pier diaphragm of the bridge was designed and detailed based on Midas-Civil results, three-dimensional Strut-and-Tie-Model (He and Liu, 2010; Wollmann et al., 2000; Hou et al., 2017), and AASHTO approximate method, section 5.8.4.5. Design of the web, top and bottom slab was based on Midas-Civil results and the details for a half section of the diaphragm are shown in Figure 2.

Four VSL type E 5-19 anchorage devices were used in each face of the diaphragm (VSL stands for Vorspann System Losinger, which is a specialist construction company). The design load " $P u$ " for each anchorage device was calculated to be:

$$
P u=0.8 \times 1.2\left(A s^{*} n^{*} p p u\right)
$$

$=0.8 \times 1.2 \times(98.7 \times 19 \times 1862 / 1000)=3352 \mathrm{kN}$, which was rounded to $3500 \mathrm{kN}$ as the design load for one anchorage device. As shown in Figure 2, each half of the diaphragm has two anchorage devices, and hence the design load for the modeled half diaphragm is $7000 \mathrm{kN}$. " $A s$ " in this equation is the area of each strand in $\mathrm{mm}^{2}$, " $n$ " is the number of strands, " $p p u$ " is the ultimate strength of the tendon in $\mathrm{MPa}$, and the equation was multiplied by 0.8 as the tendons were stressed to $80 \%$ of their ultimate strength, and multiplied by 1.2 which is the load factor for the design of anchorage zone (AASHTO, 2017).

The core of the diaphragm which was subjected to the tendon forces was designed for the following two cases (as symmetrical section, half of the diaphragm was included in the calculations):

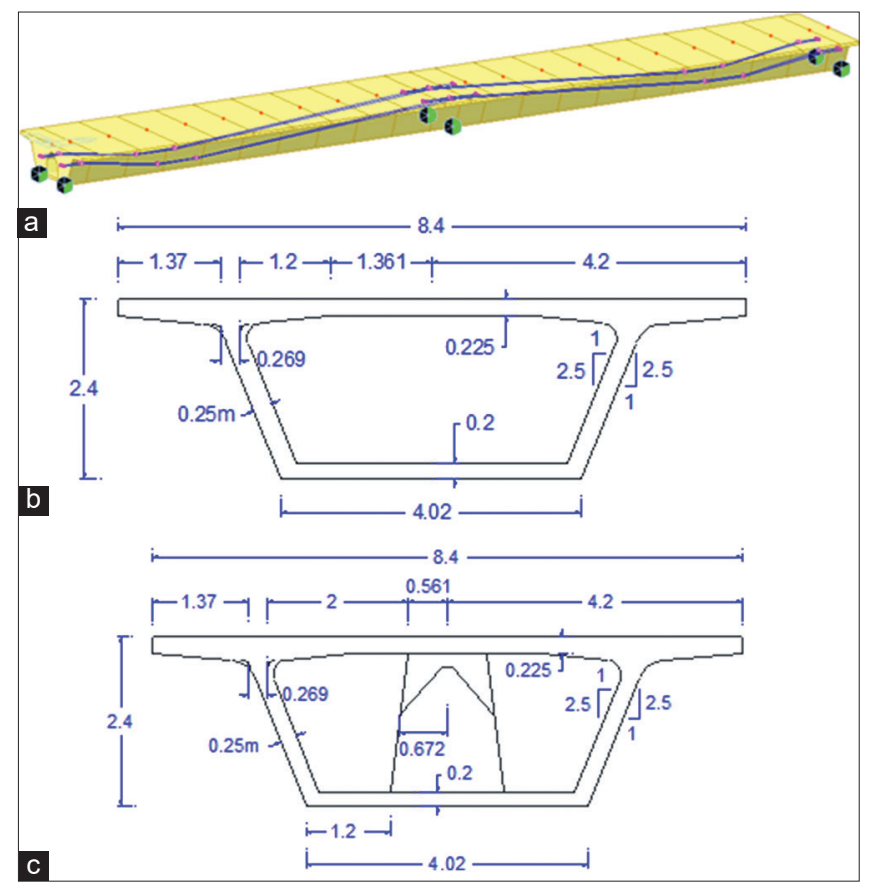

Figure 1: Typical segmental box girder bridge. (a) 3D view, (b) Cross-section for the bridge normal segment (all dimensions are in meter), (c) cross-section for the bridge diaphragm segment (all dimensions are in meter)

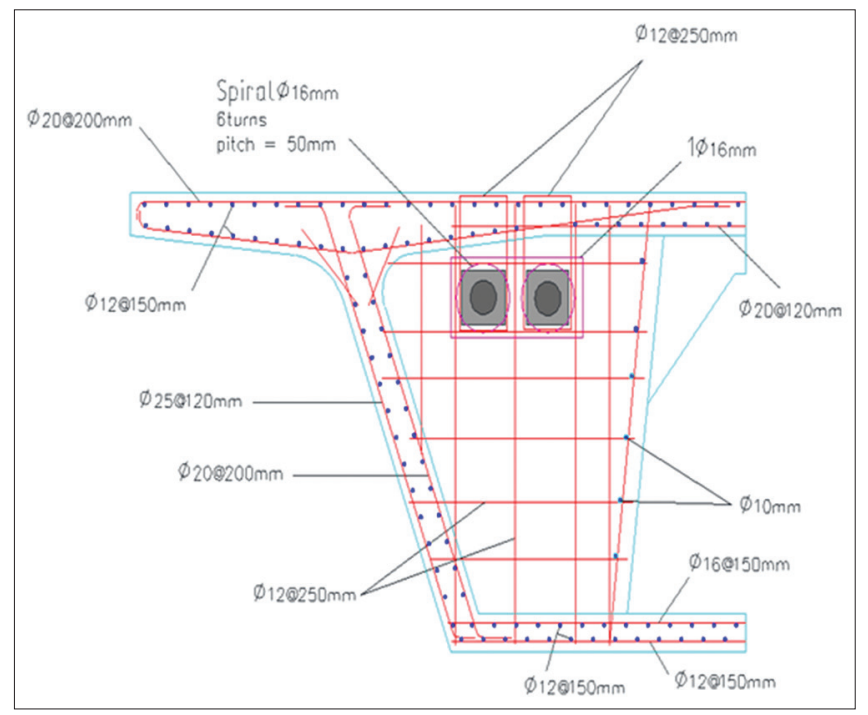

Figure 2: Reinforcement details of the interior pier diaphragm

\section{Case 1}

The tendon forces were applied on one face of the diaphragm which was supported by the top and bottom slab, and the web on the other side. Three-dimensional Strutand-Tie-Model (He and Liu, 2010; Wollmann et al., 2000; Hou et al., 2017) was used for the analysis of this case for the section (part of the diaphragm), as shown in Figure 3a. The followings are the properties of the studied section: Area, $\mathrm{A}=1.312 \mathrm{~m}^{2}$

Moment of Inertia, Ix $=1.037 \mathrm{~m}^{4}, \mathrm{Iy}=0.486 \mathrm{~m}^{4}$

Centroid, $\mathrm{x}=1.04 \mathrm{~m}, \mathrm{y}=0.97 \mathrm{~m}$ 


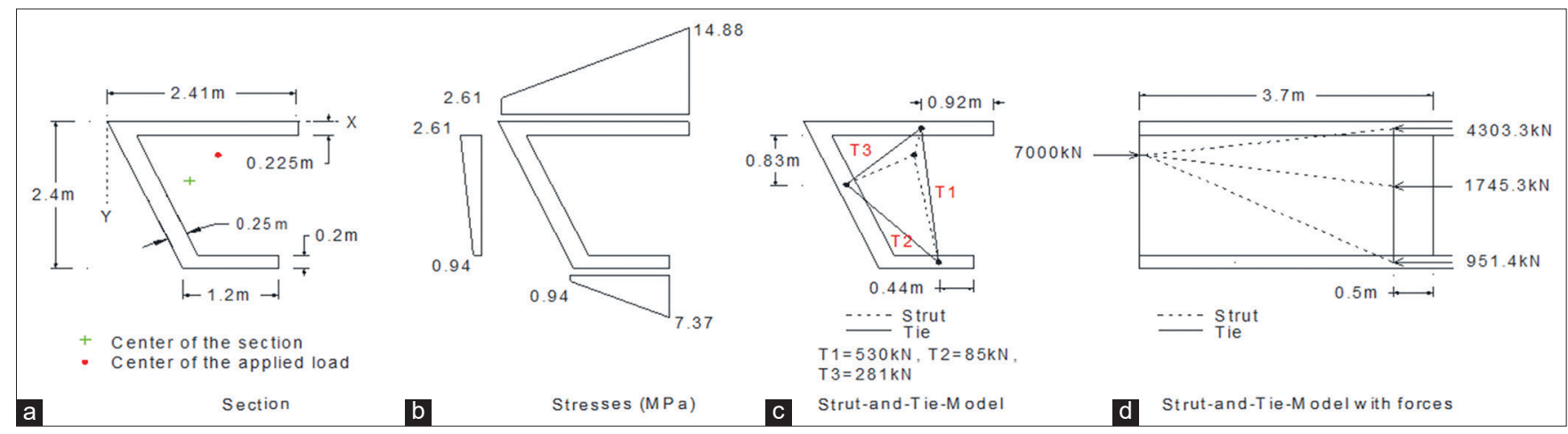

Figure 3: Strut-and-tie-model for the diaphragm

As shown in Figure 3, Pu of the two anchorage devices was applied as a concentrated load at the mid-point between them $(\mathrm{x}=1.4 \mathrm{~m}, \mathrm{y}=0.55 \mathrm{~m})$. Figure $3 \mathrm{~b}$ shows the stress magnitude and distribution for the web, bottom and top slab, which were calculated based on the beam theory. The magnitude and point of action of forces (for struts and ties model) were calculated based on the stresses and area of each part, and the results are presented in Figure $3 \mathrm{c}$ and $\mathrm{d}$.

The reinforcement for both horizontal and vertical direction was calculated at the opposite face of the applied load, for a depth of $1 \mathrm{~m}$. Yield strength of the reinforcing bars was $420 \mathrm{MPa}$, and the strength reduction factor $\varphi$ for the Strut-and Tie Model was 0.75 (ACI 318R 2014). A grid of reinforcement of $12 \mathrm{~mm}$ diameter at $250 \mathrm{~mm}$ was used for a depth of $1 \mathrm{~m}$ for each face of the diaphragm. Moreover, according to the results, stirrups with $12 \mathrm{~mm}$ diameter at $250 \mathrm{~mm}$ were provided for each anchorage device as shear-friction reinforcement.

\section{Case 2}

The tendon forces were applied at both faces of the diaphragm, as shown in Figure 4. A rectangular block model was cut from the anchorage zone and used for the calculation of the bursting forces. As shown in Figure 5a, the transvers dimensions of the block were according to AASHTO approximate method, section 5.8.4.5 that recommended a minimum edge distance of 1.5 times the corresponding lateral dimension, "a," of the anchorage plate for a proper stress distribution of the anchorage zone, and the block had the same depth of the diaphragm which was $3.7 \mathrm{~m}$.

AASHTO equations 5.8.4.5.3-1 and 5.8.4.5.3-2 were used to determine the magnitude and center of the bursting force. Following are these two equations for the case of a concentric group of anchorage devices, with non-inclined forces:

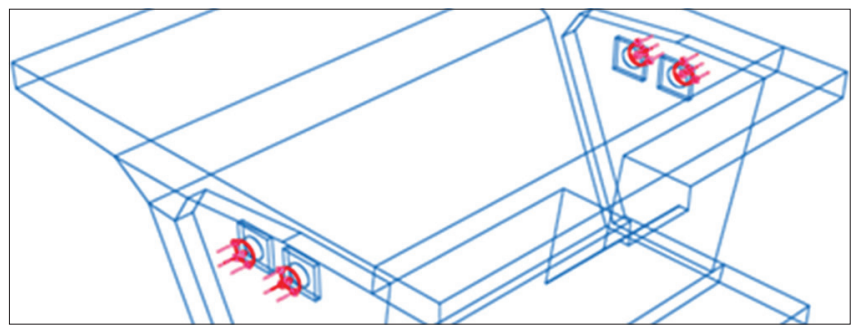

Figure 4: Tendon forces on diaphragm

$$
\begin{aligned}
& T_{\text {brust }}=0.25 \sum P u(1-a / b) \\
& d_{\text {brust }}=0.5 \mathrm{~h}
\end{aligned}
$$

Where " $a$ " is the lateral dimension of the anchorage device or group of devices in the direction considered, " $b$ " is the lateral dimension of the cross-section in the direction considered, " $\mathrm{T}_{\text {brust }}$ " is the tensile force in the anchorage zone acting ahead of the anchorage devices and transverse to the tendons axis, and " $\mathrm{d}_{\text {brust }}$ " is the distance from anchorage device to the centroid of the bursting force. Table 1 presents the input for and the results of equations (2) and (3) for the rectangular block model. Moreover, Figure $5 \mathrm{~b}$ and $\mathrm{c}$ show the dimensions and load for the long and short directions used for these equations.

Based on AASHTO section 5.9.5.6.5b, reinforcing bars (12 $\mathrm{mm}$ diameter) are required for the long direction for a minimum depth of $1638 \mathrm{~mm}$, with a maximum spacing of $288 \mathrm{~mm}$, and reinforcement bars (12 $\mathrm{mm}$ diameter) are required for the short direction for a minimum depth of $1088 \mathrm{~mm}$, with a maximum spacing of $288 \mathrm{~mm}$.

To cover both case 1 and case 2 , a grid of $12 \mathrm{~mm}$ diameter reinforcement at $250 \mathrm{~mm}$ was provided for the whole depth of the diaphragm. Moreover, anchorage devices were confined with spiral reinforcement as required by VSL, as shown in Figure 2. Anchorage zone was provided 


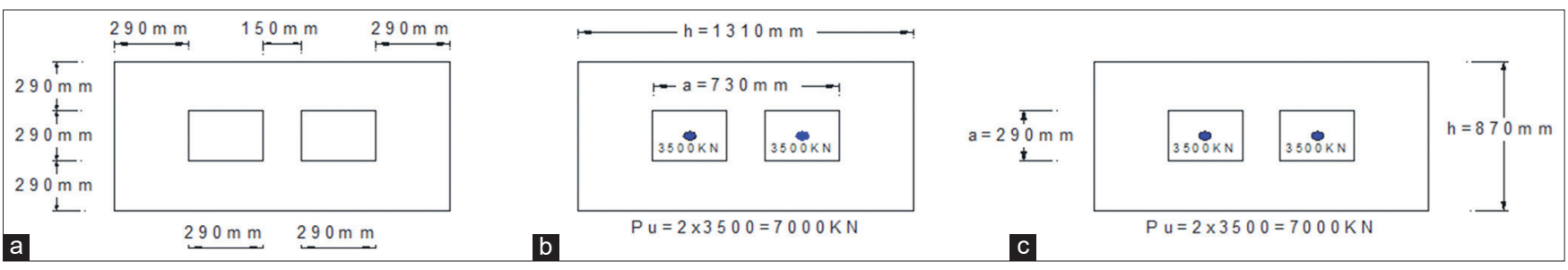

Figure 5: Anchorage zone block model. (a) Dimensions of the block, (b) dimensions and loads for long direction, (c) dimensions and loads for short

with spalling reinforcement of a closed tie of $16 \mathrm{~mm}$ diameter.

\section{COMPARISONS OF STRESSES AND FAILURE LOAD FOR THE DIAPHRAGM AND RECTANGULAR BLOCK MODEL}

\section{Development of Finite Element Model for the Diaphragm Segment}

Under ABAQUS/Explicit model, the first step was to input the geometry of the diaphragm. Damaged plasticity model was used for the concrete (Dere and Koroglu, 2017) with compressive strength $\left(f^{\prime} c\right)$ of $40 \mathrm{MPa}$ and tensile strength of 2.1 MPa. The concrete constitutive relation was based on the equation proposed by Sa'enz (Kmiecik and Kamiński, 2011) for compression, and by Wang and Hsu for tension (Kmiecik and Kamiński, 2011). Input parameters and constitutive relations for concrete material are shown in Table 2 and Figure 6. Many partitions have been used to help in meshing the diaphragm. Two anchorage plates and two wedge plate (anchorage heads) were used for each side of the diaphragm. These plates were entered in the program as isotropic elastic materials with the following properties: Young's modulus of elasticity: $200 \mathrm{GPa}$

Poisson's ratio: 0.3

Mass density: $7800 \mathrm{~kg} / \mathrm{m}^{3}$

Type of the interaction between the anchorage plates and concrete, and between anchorage plates and wedge plate was "Tie constraints." The reinforcement was modeled as embedded region within the concrete.

As shown in Figure 7a, the concrete, anchorage plates, and wedge plates were meshed using hexagon element (eight nodes brick), while for the reinforcement, a 2-node threedimension truss element was used. Size of all elements was $100 \mathrm{~mm}$. The red shaded area in Figure 7b is the diaphragm support in Y direction that represents the diaphragm bearing pad.

\section{Rectangular Block Model}

As shown in Figure 7c, a rectangular block was cut from the anchorage zone of the diaphragm for the comparison

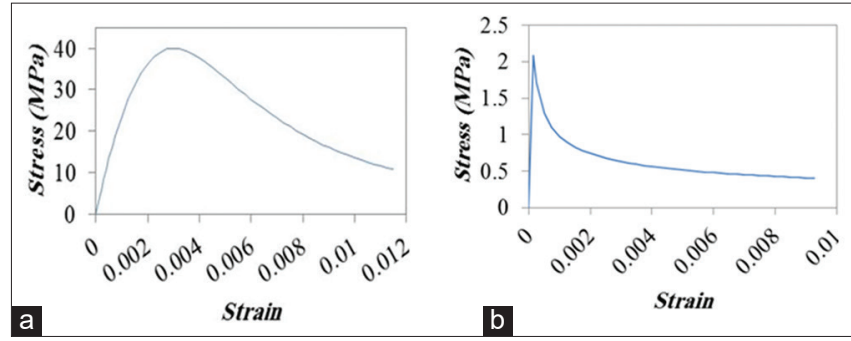

Figure 6: Concrete constitutive model. (a) Compression, (b) tension

Table 1: AASHTO equations input and results

\begin{tabular}{lcccccc}
\hline Direction & \multicolumn{3}{c}{ Equations input } & & \multicolumn{2}{c}{ Equations results } \\
\cline { 2 - 4 } & Pu $\mathbf{k N}$ & $\mathbf{a ~} \mathbf{~ m m}$ & $\mathbf{h ~} \mathbf{~ m m}$ & & $\mathbf{T}_{\text {brust }} \mathbf{k N}$ & $\boldsymbol{d}_{\text {brust }} \mathbf{m m}$ \\
\hline Long & 7000 & 730 & 1310 & & 775 & 655 \\
Short & 7000 & 290 & 870 & & 1167 & 435 \\
\hline
\end{tabular}

Table 2: Plasticity parameters of concrete material model

\begin{tabular}{lcccc}
\hline Dilatation angle & Eccentricity & $\mathbf{f}_{\mathrm{b} 0} / \mathrm{f}_{\mathrm{c} 0}$ & $\mathrm{~K}$ & Viscosity \\
\hline 15 & 0.1 & 1.16 & 0.67 & 0 \\
\hline
\end{tabular}

purposes, and the transvers dimensions of the block which are shown in Figure 5 were selected according to the AASHTO approximate method, section 5.8.4.5. This block has the same depth of the diaphragm of $3.7 \mathrm{~m}$, and is symmetric in longitudinal direction. Hence one half of this block is included in the analysis and the final rectangular block model for the study is shown in Figure $7 \mathrm{~d}$ that has a depth of $1.85 \mathrm{~m}$. As shown in Figure 7e, one side of the block was loaded and the other side supported uniformly (the yellow shaded area). Finite element modeling and meshing of the block were similar to the model of the diaphragm.

\section{Analysis}

Two rounds of analysis were conducted for the diaphragm and the rectangular block model. The first analysis was to determine the failure load of the models, and the anchorage heads were loaded (as displacement), and the load was increased gradually up to failure. The aim of this round was to compare the failure load of the diaphragm and rectangular block model, from the load-displacement 


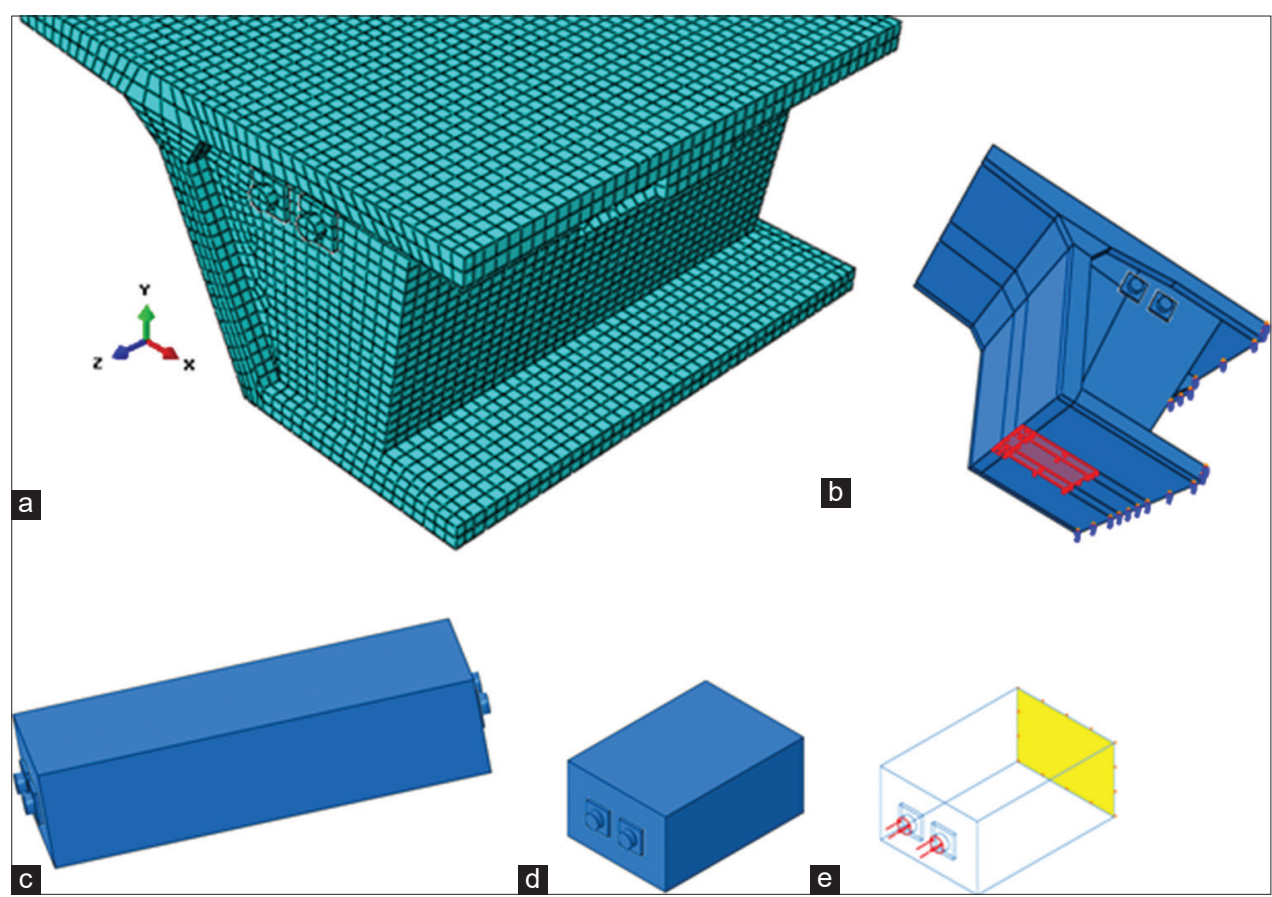

Figure 7: Finite element models. (a) Diaphragm, (b) diaphragm supports, (c) full block, (d) rectangular block model, (e) block loads and supports

charts, without using factors of safety. The second round of the analysis was to compare stresses of the two models at design load. The second analysis included applying a constant load of $3500 \mathrm{kN}$ on each of the two anchorage heads.

\section{RESULTS}

A comparison of the failure load was made between the diaphragm and rectangular block model, and as shown in Figure 8, the failure load of the diaphragm was $19,700 \mathrm{kN}$ compared to the block which was $19,340 \mathrm{kN}$. These results are very close as the failure load of the diaphragm is only $2 \%$ more than the failure load of the block. The total longitudinal displacement at the failure load was measured at the top of wedge plate, and the displacements for the diaphragm and rectangular blocks were $13.6 \mathrm{~mm}$ and $5.9 \mathrm{~mm}$, respectively. The displacement of the rectangular block was almost $50 \%$ of the displacement of the diaphragm (the block had a half depth of the diaphragm). Hence, the displacement of the rectangular block with full depth, shown in Figure 7c, will be twice the value of $5.9 \mathrm{~mm}$ which is $11.8 \mathrm{~mm}$ and is close to the displacement of the diaphragm of $13.6 \mathrm{~mm}$.

The stresses magnitude and distribution of the rectangular block model were compared with the diaphragm, as shown in Figure 9, this comparison was done through different longitudinal paths in the direction of $\mathrm{Z}$-axis for both models. Figure 10 presents

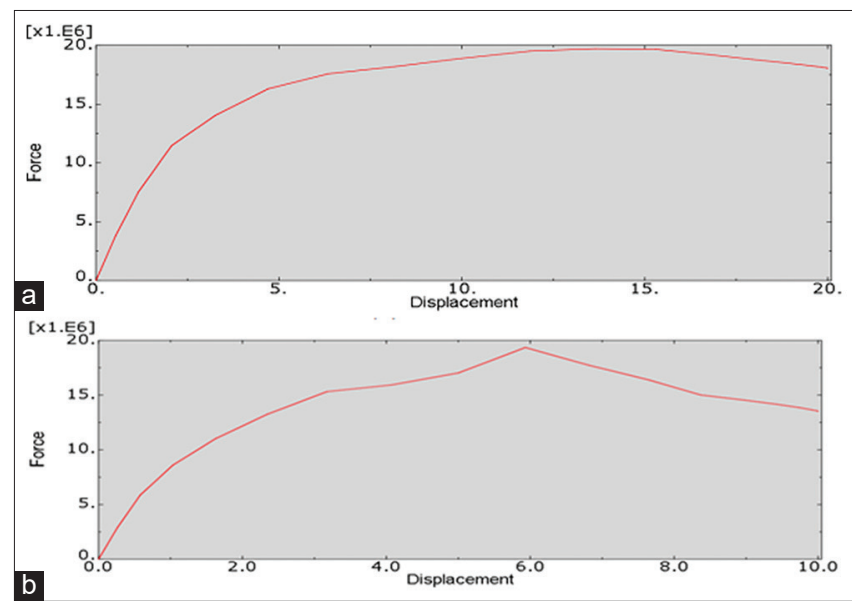

Figure 8: Relationship between applied load (Newton) and displacement ( $\mathrm{mm}$ ). (a) Diaphragm, (b) rectangular block

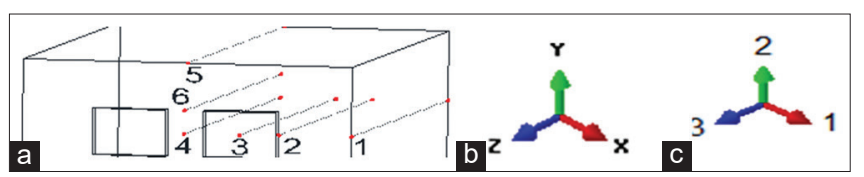

Figure 9: Paths and axis for stresses comparison. (a) Paths, (b) global axis, (c) axis for stresses names

the stress distribution for the block and the diaphragm; stress distributions through the paths are very close for the two cases. The first three letters in stress symbols represent the stresses considered, and the past two latters are the path number through which the stresses were plotted. For example, S11-P4 stands for S11 [stresses according to the axis in Figure 9c] plotted through Path 
4 [according to Figure 9a]. It can be noticed that S22-P4 for the rectangular block starts from zero as the block is completely symmetric regarding the stress in the direction of axis 2 at the starting point of path 4 . This is not the same case for S11 as the displacement of the two plates at both sides of starting point of path 4 will create stress in direction of axis 1.
Figures 11-13 present stress contours in sections and planes through different paths. In these figures, stress contours in the left side are for the diaphragm and in the right side for the rectangular block. For S11 and S22 [Figures 11 and 12] more detailed range of tensile stresses, compared to the compressive stresses, is shown. The stress contours are very similar for the two models.

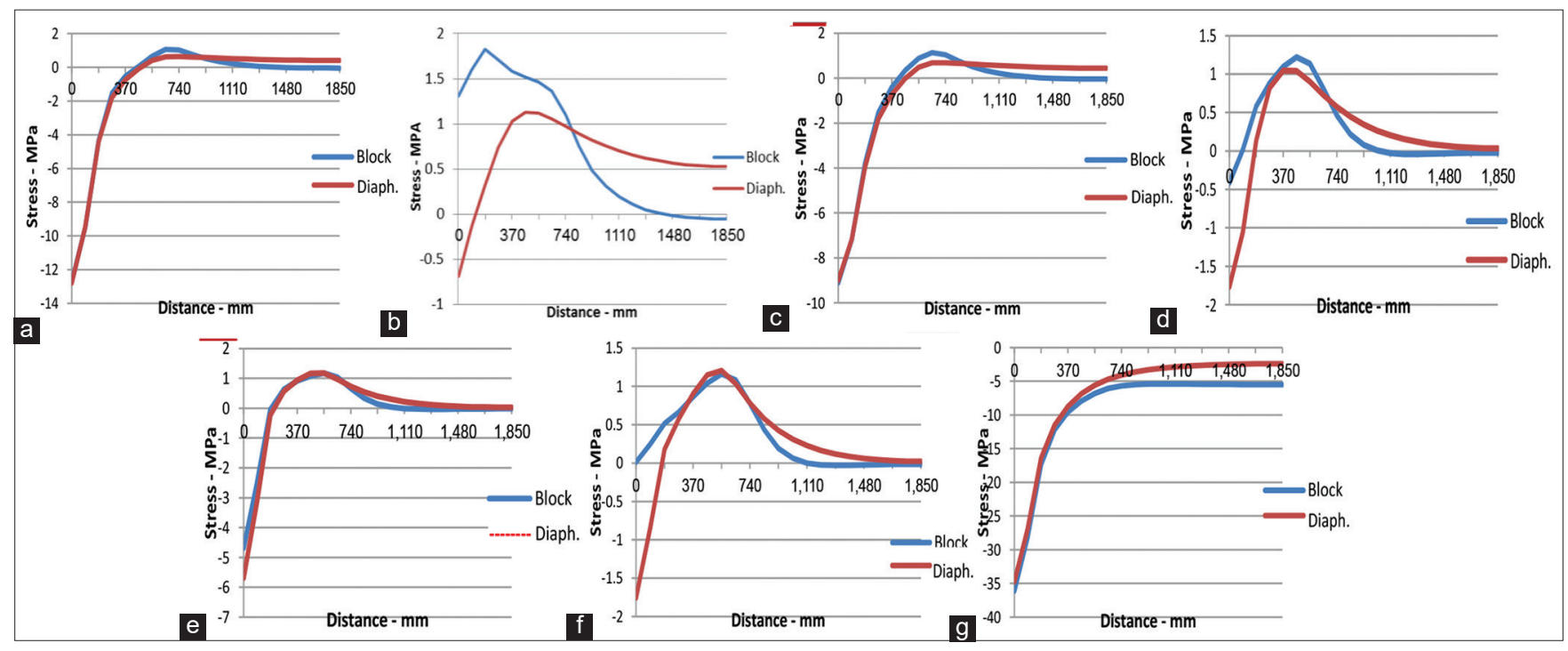

Figure 10: Stresses in different paths. (a) S11-P4, (b) S11-P5, (c) S11-P6, (d) S22-P2, (e) S22-P3, (f) S22-P4, (g) S33-P3

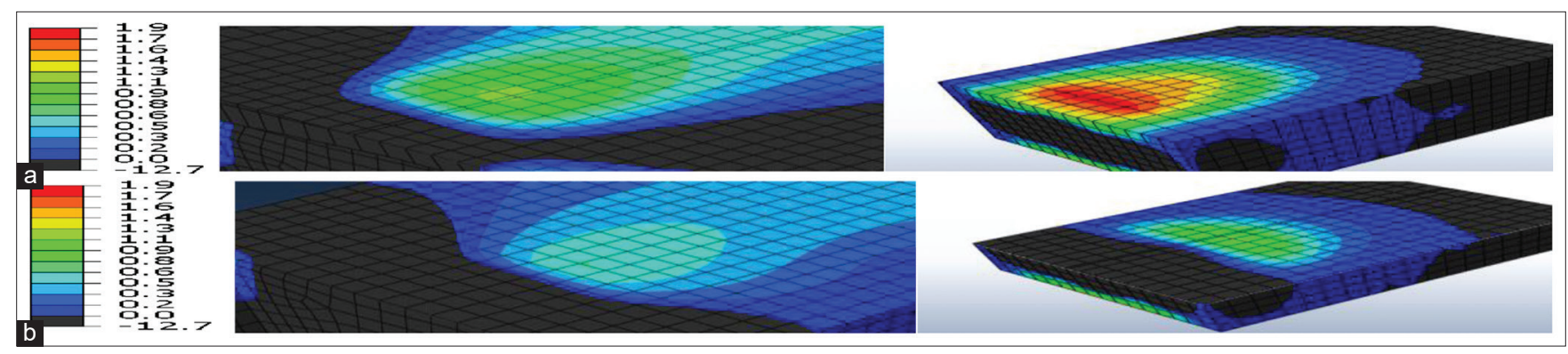

Figure 11: Stress contours-S11 (MPa) in different sections. (a) Horizontal section through Path 5, (b) horizontal section through Path 4

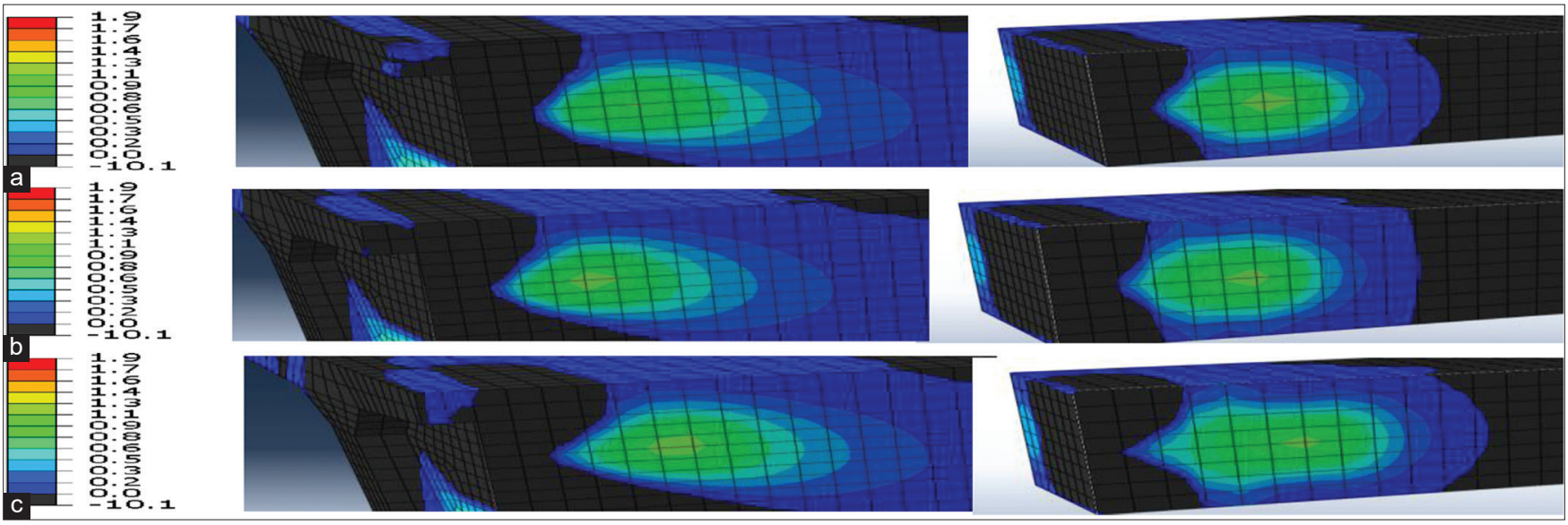

Figure 12: Stress contours-S22 (MPa) in different sections. (a) Vertical section through Path 2, (b) vertical section through Path 3, (c) vertical section through Path 4 


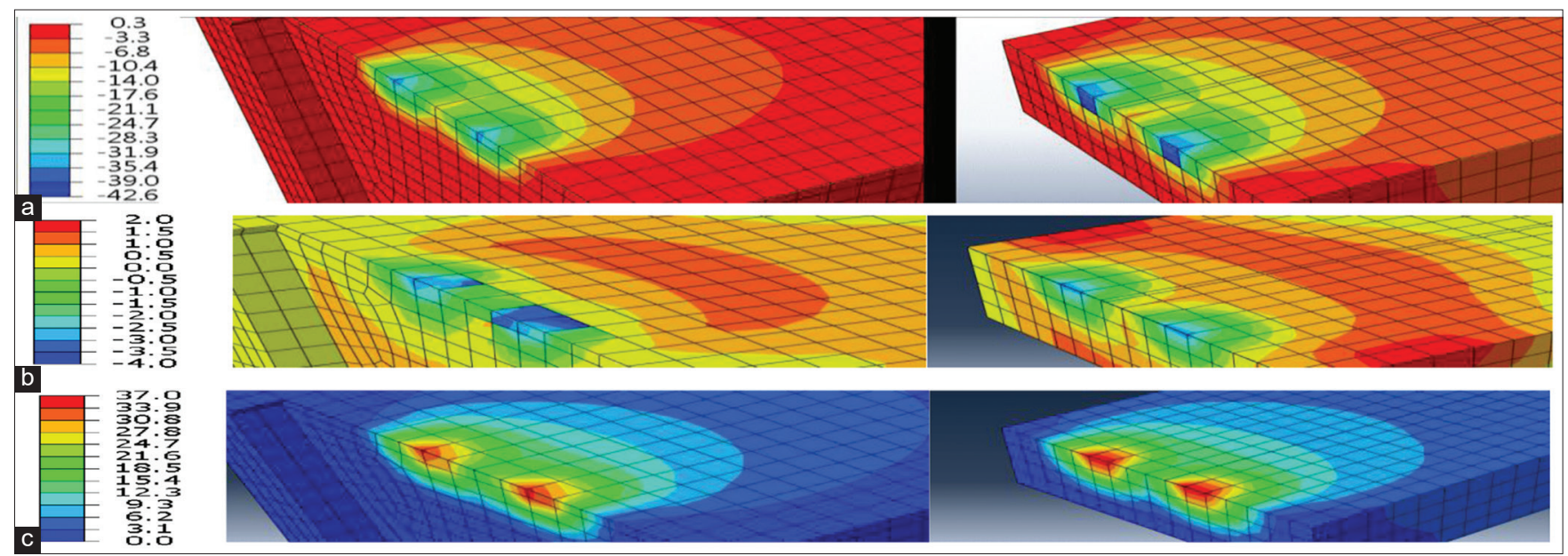

Figure 13: Different stress contours (MPa) in a horizontal section through Path 4. (a) S33, (b) Maximum principal, (c) Mises

\section{CONCLUSIONS}

The magnitude and distribution of stresses and the failure load for the models of the rectangular block and the diaphragm included in this study were very close. For the case of interior pier diaphragm subjected to the prestressing forces from both sides, a rectangular block cut from the anchorage zone with the transverse dimensions according to AASHTO approximate method, section 5.8.4.5, represents a good model for stress distribution and failure load of this area. Moreover, the longitudinal displacement at failure load for the modeled rectangular block was almost $50 \%$ of the displacement of the diaphragm. The displacement of the block with full depth was close to the displacement of the diaphragm.

These results will serve to simplify the modeling of anchorage zone for the diaphragm and help in analysis, theoretical and experimental parametric studies of this area.

\section{REFERENCES}

American Association of State Highway Transportation Officials. 2017. American Association of State Highway and Transportation Officials LRFD Bridge Construction Specifications. $8^{\text {th }}$ ed. American Association of State Highway Transportation Officials, Washington, DC.

American Concrete Institute. 2014. Building Code Requirements for Structural Concrete. American Concrete Institute, United States.

Breen, J., O. Burdet, C. Roberts, D. Sandres and G. Wollmann. 1994. Anchorage Zone Reinforcement for Post-tensioned Concrete
Girders. National Cooperative Highway Research Program Report, No. 356, Washington, DC.

Burdet, O. 1990. Analysis and Design of Post-tensioned Anchorage Zones in Concrete Bridges. Ph.D. Dissertation. The University of Texas at Austin, Austin.

Dere, Y. and M. Koroglu. 2017. Nonlinera FE modeling of reinfoced concrete. Int. J. Struct. Civil Eng. Res. 6: 71-74.

Florida Department of Transportation. 2017. Structural Design Guidline. Vol. 1. FDOT Structural Manual, USA.

Florida Department of Transportation. 2018. Structures Detailing Manual, Structures Manual. Vol. 2. Florida Department of Transportation, USA.

He, Z. and Z. Liu. 2010. Optimal three-dimensional strut-and-tie models for anchorage diaphragms in externally prestressed bridges. Eng. Struct. 32: 2057-2064.

Hou, D., J. Zhao, J. Shen and J. Chen. 2017. Investigation and improvement of strut-and-tie model for design of end anchorage zone in post-tensioned concrete structure. Constr. Build. Mater. 136: 482-494.

Johnson, S. 2006. Analytical Modeling of Fiber Reinforced Posttensioned Concrete Anchorage Zones. Master's Thesis. Florida State University, USA.

Kmiecik, P. and M. Kamiński. 2011. Modelling of reinforced concrete structures and composite structures with concrete strength degradation taken into consideration. Arch. Civil Mech. Eng. 6: 623-636

Sanders, D. 1990. Design and Behavior of Anchorage Zones in Post-tensioned Concrete Members. Ph.D. Dissertation. The University of Texas at Austin, Austin.

Tawfiq, K. and B. Robinson. 2008. Post-tensioned Bridge Girder Anchorage Zone Enhancement with fiber Reinforced Concrete. Final Report Submitted to the Florida Department of Transportation, Florida A and M University.

Wollmann, G., J. Breen and M. Kreger. 2000. Anchorage of external tendons in end diaphragms. J. Bridge Eng. 5: 208-215. 